\title{
The Association between Self-Reported Energy Intake and Intra-Abdominal Adipose Tissue in Perimenopausal Women
}

\author{
Rasa Kazlauskaite, Kelly Karavolos, Imke Janssen, Kimberly Carlson, Karla J. Shipp, \\ Sheila A. Dugan, and Lynda H. Powell
}

Rush Center for Urban Health Equity, Department of Preventive Medicine, Rush University Medical Center, 1700 W Van Buren Street, Suite 470, Chicago, IL 60612, USA

Correspondence should be addressed to Rasa Kazlauskaite, rasa_kazlauskaite@rush.edu

Received 7 February 2012; Accepted 19 April 2012

Academic Editor: Mark A. Pereira

Copyright ( $\odot 2012$ Rasa Kazlauskaite et al. This is an open access article distributed under the Creative Commons Attribution License, which permits unrestricted use, distribution, and reproduction in any medium, provided the original work is properly cited.

We have previously shown that physical activity predicts intra-abdominal adipose tissue (IAT), but it is unknown whether energy intake predicts IAT independently of physical activity in a community-based, naturalistic environment. The association of energy intake with IAT was explored cross-sectionally in women, recruited between 2002 and 2005 for a study of fat patterning in midlife. IAT at $\mathrm{L}_{4}-\mathrm{L}_{5}$ vertebral interspace was assessed by computed tomography, energy intake by the Block Food Frequency Questionnaire, and physical activity by the Kaiser Physical Activity Survey. Linear regression models were used for the principal analyses. Among the 257 women, 48\% were African American and 52\% were Caucasian. Women were $52 \pm 3$ years old, and $49 \%$ were postmenopausal. Every $500 \mathrm{kcal}$ increase in energy intake was associated with a $6 \%$ higher IAT $(P=0.02)$, independent of physical activity $(P=0.02)$, after adjustment for ethnicity, menopausal status, age, smoking, income, and DXA-assessed percent body fat. Energy intake had a significant interaction with ethnicity $(P=0.02)$, but not with physical activity. Models using the IAT to subcutaneous abdominal adipose tissue ratio as an outcome had similar associations. In conclusion, self-reported EI was associated with preferential IAT accumulation in midlife women, independent of physical activity. This association was significantly stronger in Caucasian than African American women. Future longitudinal studies are needed to explore lifestyle predictors of IAT accumulation during the menopausal transition.

\section{Introduction}

Abdominal obesity, characterized by preferential accumulation of intra-abdominal adipose tissue (IAT), contributes to cardiovascular and metabolic risk beyond the risk defined by body mass index $[1,2]$ Thus, prevention of abdominal obesity is key to reducing cardiometabolic risk [3].

Preferential IAT accumulation, as measured by IAT adjusted for percent body fat or IAT to subcutaneous abdominal adipose tissue (SAT) ratio, depends on genetic factors (e.g., ethnicity or gender), smoking [4], and the hormonal milieu (e.g., postmenopausal status) $[5,6]$. The IAT compartment is highly active during changes in balance between energy intake (food consumption) and energy expenditure (physical activity). Rapid IAT accumulation occurs in acute overfeeding experiments [7], and preferential reduction of
IAT volume is characteristic of immediate and acute weight loss [8], but mitigated after 12-14 weeks of intervention [9].

We have shown that lack of regular moderate physical activity (not meeting physical activity guidelines for healthy adults) is associated with preferential IAT accumulation in midlife women, independent of age, menopausal status, income, smoking, and percent body fat [6], suggesting that a sustained change in lifestyle may affect preferential IAT accumulation. However, physical activity may not be the only lifestyle target for preventing IAT accumulation [4]. Although energy intake is linked to IAT in laboratory studies, no population-based studies have been conducted and no studies have determined whether or not energy intake is associated with preferential IAT accumulation, independently of physical activity. Moreover, there have been no studies that examined whether these relationships are 
moderated by ethnicity or menopausal status in midlife women. Answers to these questions are important because they can inform the design of lifestyle interventions aimed at decreasing cardiometabolic risk by decreasing preferential accumulation of IAT in midlife women.

\section{Methods and Procedures}

2.1. Participants. Participants were women who enrolled in an ancillary study of the Study of Women's Health Across the Nation (SWAN) at the Chicago site. This ancillary study, the "SWAN Fat Patterning Study", was designed to investigate the impact of the menopausal transition on IAT accumulation [5]. SWAN is a seven-site, multiethnic longitudinal study of women transitioning through menopause, featuring ongoing annual evaluations. At enrollment into the SWAN, between 1996 and 1997, eligible women were 42-52 years old, reported a menstrual period within the past 3 months, did not use medications known to affect pituitary or ovarian function, and did not use exogenous hormones within the 3 months preceding the baseline interview. A unique feature of the Chicago SWAN site was that it used a population-based recruitment strategy, drawing on a complete community census, to recruit a representative sample of Caucasian and African American women in which the confound between ethnicity and socioeconomic status was minimized. Details of SWAN recruitment and the study protocol have been reported [10].

Women enrolled in the Chicago SWAN Fat Patterning Study between August 2002 and December 2005, coincident with annual SWAN follow-up visits 4 through 9. Eligible women did not have diabetes, chronic liver or kidney disease, substance abuse or eating disorders, were not pregnant, had no breast or joint implants, and weighed less than 300 pounds. Details of recruiting were reported previously $[5,6]$.

Of the 386 eligible Chicago SWAN participants, 297 $(77 \%)$ enrolled in this SWAN Fat Patterning Study, and they did not differ from the remaining women in any of the baseline characteristics. Four were excluded from analytical sample because of hysterectomy (due to difficulty assessing natural menopause), four were excluded due to diabetes (as diabetes and treatment for diabetes contribute to IAT accumulation), two were excluded because they did not have an IAT measurement, and 30 (10\%) were excluded because they were receiving menopausal hormone therapy (as estrogen and progesterone use may potentially affect appetite, adipose tissue accumulation, and distribution [11]). The final analytic cohort of eligible women, which consisted of 257 women, represented $86 \%$ of the original 297 participants.

2.2. Assessment of Adipose Tissue. IAT and subcutaneous abdominal adipose tissue (SAT) were assessed by a computerized tomography (CT) scan of the abdomen using a General Electric Lightspeed VCT scanner (General Electric Medical Systems, Milwaukee, WI) at the $\mathrm{L}_{4}-\mathrm{L}_{5}$ intervertebral space in a single $10 \mathrm{~mm}$ thick image. Scanned images were analyzed at the University of Colorado Health Sciences Center using their software (RSI, Boulder, CO), as described previously $[5,6]$. A relative index of IAT accumulation was calculated as a ratio of IAT to SAT [2].

Percent body fat (\%) was calculated as total body fat mass/(total body fat mass + total lean body mass) $\times$ 100. Total body fat mass (in kilograms) was assessed the same day as IAT by dual-energy X-ray absorptiometry, using a General Electric Lunar Prodigy scanner (GE-Lunar, Madison, WI), and analyzed using enCORE software (GELunar), as described previously [6].

2.3. Assessment of Energy Intake. Energy intake was selfreported. At baseline, year 5, and year 9 annual visits, women completed a modified version of the 1995 Block interviewerassisted semiquantitative food frequency questionnaire [12]. The food frequency questionnaire was administered in English and reflected the "usual" dietary pattern for the previous year. Individual energy intake per day was calculated using DietSys software (http://appliedresearch. cancer.gov/DietSys/software.html) [13]. Pearson correlations between initial measures with repeated measures of FFQ energy intake were 0.70 , and the coefficient of variation was $2.7 \%[14]$.

Measurement error that occurs when assessing person's usual diet with a Food Frequency Questionnaire generally involves bias related to true intake in addition to random variation [15]. Bias related to true intake often occurs as the "flattened-slope phenomenon" (consumers with high levels of intake tend to underreport and lowlevel consumers tend to overreport), which biases the betacoefficient upward. Energy intake is derived from the Food Frequency Questionnaire, and thus subject to measurement error [14]. Because biomarker validation studies were not performed in SWAN, we adjusted energy intake, using factors previously shown in other studies using biomarkers [14] to correct for measurement error: income, ethnicity, age, physical activity, and a measure of body size. We did not use exact regression coefficients derived from other studies, as the patient population and food frequency questionnaire differed in our study.

2.4. Assessment of Physical Activity. Physical activity was assessed using an adapted version of the Kaiser Physical Activity Survey [16]. It was administered at the SWAN follow-up visits 3, 5, 6, and 9. The assessment selected for analysis was the one that was closest to the adipose tissue assessment, as described previously [6]. A total activity score was created by summing across Kaiser Physical Activity Survey (KPAS) domains (Sports/Exercise, Active Living Habits, Housework/Caregiving), with a higher score indicating higher activity, as described previously [6]. The Cronbach's alpha coefficient for KPAS score in midlife women ranged from $0.66-0.80$ [17].

2.5. Assessment of Menopausal Status. Menopausal status was defined at the time of intra-abdominal adipose tissue assessment. The women were grouped into (a) 
pre-/perimenopausal (pre-, early peri-, and late perimenopause) and (b) postmenopausal groups. The postmenopausal women had their final menstrual period more than 12 months prior to the IAT assessment. Women who had menstrual bleeding during the previous 12 months were classified as pre-/perimenopausal.

2.6. Other Variables. Height, weight, and waist girth were measured using a standard anthropometric measurement protocol. Weight was measured to the nearest $0.1 \mathrm{~kg}$ at each annual examination on digital scale while participants stood in stocking feet and light clothing. Waist girth was measured annually to the nearest $0.1 \mathrm{~cm}$ with a measuring tape placed horizontally around the participant at the narrowest part of the torso, and an average of two measurements was reported. Self-administered and interviewer-administered questionnaires were used to assess social, economic, behavioral, psychological, health, and lifestyle characteristics [10]. Ethnicity was self-reported as either African-American or Caucasian. Age (in years) was a variable created as the difference between IAT assessment date and self-reported date of birth and modeled continuously in all analyses. Participant's annual household income was classified into three levels : less than $\$ 50,000, \$ 50,000$ to $\$ 75,000$, or greater than $\$ 75,000$.

\section{Design and Data Analysis}

Data for the principal outcome (IAT area) were collected at the baseline of the ancillary SWAN Fat Patterning Study, which corresponded to SWAN annual visit 4, 5, or 6, dependent on the timing of recruitment. However, data for the primary predictor variable (energy intake) were collected only at the SWAN study baseline, visit 5, and visit 9 .

To handle differences in the timing of assessments of IAT and energy intake, we used an interpolation technique for the energy intake variable $[18,19]$. After checking for linearity of energy intake trends over time, we used a random effects model with random intercept and slope to estimate energy intake over time in the SWAN study (between baseline, year 5 and year 9). These models yielded participant-specific intercepts and slopes, which were weighted averages of the regression coefficients for the full sample and the regression coefficients from each participant's data [19]. These slopes were used to estimate energy intake at the time of IAT assessment. To assess the performance of these interpolation models, we compared fitted values with observed values from baseline, visit 5, and visit 9. We ran the Pearson correlations between fitted and observed values which produced $r=$ $0.89(P<0.0001)$, indicating a strong agreement. In addition, linear regressions of observed values on fitted values indicated no systematic bias, as intercepts were close to 0 and slopes were close to 1 .

Descriptive statistics were used to summarize the participants' energy intake, age, ethnicity, income, education, menopausal status, physical activity, smoking, body mass index, waist girth, and other adipose tissue measurements. Logarithmic transformation of IAT area was used in linear regression models, as this primary outcome did not follow a normal distribution.

We employed a series of linear regression models using log-transformed IAT as a dependent variable and interpolated energy intake as our primary predictor with adjustments for ethnicity, age, income, percent body fat, menopausal status, smoking, and physical activity. The energy intake was reported in $500 \mathrm{kcal}$ increments and percent body fat was reported in 5\% increments in body fat. To adjust for possible nonlinear association between (i) IAT and percent body fat and (ii) IAT and age, these covariates were entered in the model as both linear and centered quadratic terms [19]. The continuous variables in the model were IAT area, percent body fat (and its centered quadratic transformation), age (and its centered quadratic transformation), and physical activity. The categorical variables in the models were income, ethnicity, smoking, and menopausal status. Reference groups for these variables were Caucasian for ethnicity; pre-/perimenopause for menopausal status; and nonsmokers for smoking status. The latter three were binary variables. The high-income group was the reference group for the categorical (trichotomous) income variable. All model assumptions were checked and model fit was assessed graphically via residual plots.

Model 1 was constructed to evaluate the relationship between energy intake and IAT after adjustment for (i) confounders (ethnicity and menopausal status), and (ii) correction factors (age, percent body fat, smoking, and income) [20]. Model 2 was constructed to evaluate the relationship between energy intake and IAT after adjustment for (i) physical activity in addition to covariates used in the first model. Model 3 was designed to explore interactions of energy intake with ethnicity and menopausal status, adjusting for the factors in model 2. Analogous models 1 through 3 were constructed using IAT:SAT ratio as a dependent variable to assess the predictors of IAT per quantity of SAT. To interpret the coefficients from the linear model, we estimated the percentage change in the average value of IAT area per unit increase in energy intake multiplied by $100(100 \times \beta)[21]$.

All analyses were conducted using SAS, PC version 9.2 (SAS Institute Inc., Cary, NC).

\section{Results}

Table 1 depicts participant characteristics. In this diverse cohort of 257 women, $48 \%(n=123)$ were African American and $52 \%(n=134)$ were Caucasian. Fifty-three percent had an annual household income above $\$ 75,000$, and $61 \%$ had a college education or higher degree. At the time of IAT assessments, women were on average 52 years old (ranging from 47 to 61 ), $46 \%$ were obese (body mass index (BMI) $\geq$ $\left.30.0 \mathrm{~kg} / \mathrm{m}^{2}\right)$, and $30 \%$ were overweight $(\mathrm{BMI}=25.0-29.9 \mathrm{~kg} /$ $\left.\mathrm{m}^{2}\right)$. Waist girth was $90.3 \pm 13.3 \mathrm{~cm}$. Forty-nine percent $(n=$ 125) were postmenopausal, and the remaining participants were pre- or perimenopausal.

Participants' self-reported energy intake corresponding to the respective SWAN Fat Patterning Study visit was an average of $1608 \pm 470 \mathrm{kcal} / 24 \mathrm{~h}$. 
TABle 1: Participant characteristics.

\begin{tabular}{|c|c|}
\hline Participant characteristics & $\begin{array}{c}\text { All women } \\
N=257\end{array}$ \\
\hline \multicolumn{2}{|l|}{ Demographic characteristics } \\
\hline Age, years $($ mean $\pm S D)$ & $52 \pm 3$ \\
\hline African American, $n(\%)$ & $123(48)$ \\
\hline Proportion of postmenopausal, $n(\%)$ & $125(49)$ \\
\hline \multicolumn{2}{|l|}{ Marital status, $n(\%)$} \\
\hline Single & $23(9)$ \\
\hline Previously married & $71(28)$ \\
\hline Married & $163(63)$ \\
\hline \multicolumn{2}{|l|}{ Education, $n(\%)$} \\
\hline High school or less & $30(12)$ \\
\hline Some college & $67(27)$ \\
\hline College degree & $58(24)$ \\
\hline Postgraduate degree & $90(37)$ \\
\hline \multicolumn{2}{|l|}{ Annual household income, $n(\%)$} \\
\hline lower than $\$ 50,000$ & $62(24)$ \\
\hline$\$ 50,000$ to $\$ 75,000$ & $58(23)$ \\
\hline$\$ 75,000$ or greater & $135(53)$ \\
\hline \multicolumn{2}{|l|}{ Measurements of adiposity } \\
\hline Body mass index, $\mathrm{kg} / \mathrm{m}^{2}($ mean $\pm \mathrm{SD})$ & $29.7 \pm 6.2$ \\
\hline Waist girth, $\mathrm{cm}($ mean $\pm \mathrm{SD})$ & $90 \pm 13$ \\
\hline Absolute fat mass, $\mathrm{kg}$ (mean $\pm \mathrm{SD})$ & $35 \pm 13$ \\
\hline Percent body fat, $\%($ mean \pm SD $)$ & $44 \pm 8$ \\
\hline \multicolumn{2}{|l|}{ Regional adipose tissue (geometric mean \pm SD) } \\
\hline Intra-abdominal (IAT) area, $\mathrm{cm}^{2}$ & $101 \pm 52$ \\
\hline Subcutaneous abdominal (SAT) area, $\mathrm{cm}^{2}$ & $409 \pm 161$ \\
\hline IAT/SAT Ratio & $0.3 \pm 0.1$ \\
\hline \multicolumn{2}{|l|}{ Lifestyle factors } \\
\hline Energy intake, $\mathrm{kcal} / 24 \mathrm{~h}($ mean $\pm \mathrm{SD})$ & $1608 \pm 470$ \\
\hline Kaiser Physical Activity Survey score $($ mean \pm SD) & $8 \pm 2$ \\
\hline Current smokers, $n(\%)$ & $51(20)$ \\
\hline
\end{tabular}

4.1. Intra-Abdominal Adipose Tissue Area. Table 2, Model 1 shows that self-reported energy intake was associated with preferential IAT accumulation: every 500 calories of energy intake were related to a $6 \%$ higher IAT $(P=0.025)$, after adjustment for ethnicity, menopausal status, smoking, income, age, and percent body fat.

Table 2, Model 2 shows that both energy intake and physical activity contributed independently to IAT. The addition of physical activity into the model did not weaken the association between energy intake and IAT.

Table 2, Model 3 shows a significant interaction between self-reported energy intake and ethnicity $(P=0.02)$. As depicted in Figure 1, the association between energy intake and preferential IAT accumulation was considerably stronger in Caucasian women compared to African American women. The relationship between energy intake and IAT was not significantly moderated by physical activity or menopausal status.

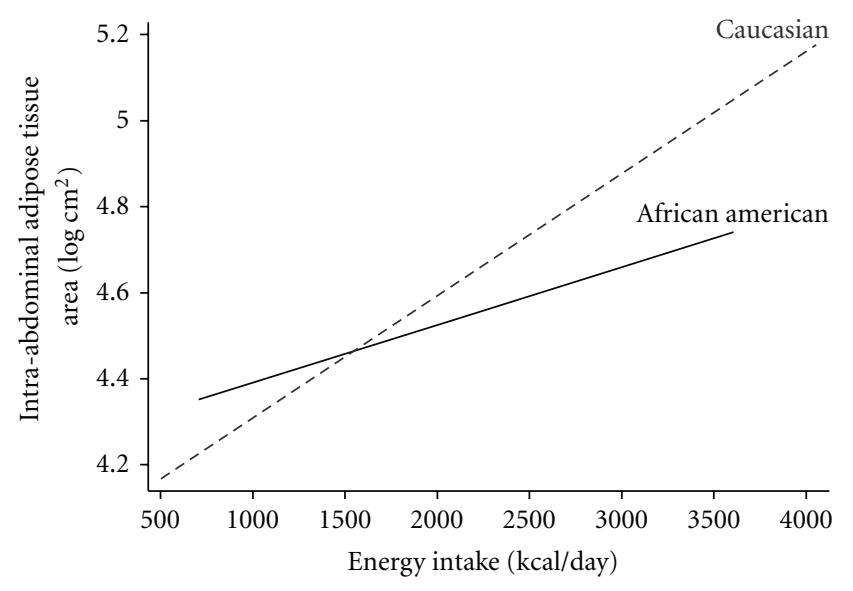

Figure 1: Intra-abdominal adipose tissue and energy intake in African American (solid line) and Caucasian (dashed line) women, adjusted for physical activity, menopausal status, smoking, income, age, and percent body fat (the predicted IAT values were calculated based on Model 3 described in Table 2). Energy intake by ethnicity interaction $\beta=-0.120, P=0.018$.

\section{Relative Index of Intraperitoneal Abdominal Adipose Tissue Accumulation}

An alternative approach to explore preferential IAT accumulation is to use the ratio IAT:SAT as the outcome. This is a relative index of IAT accumulation, which is associated with higher cardiometabolic risk [2].

Table 3 contains Models 1, 2, and 3 with IAT: SAT ratio as a dependent variable. The results are virtually identical to those obtained using IAT as the outcome. However, the model for IAT:SAT ratio explains less of the variance, as indicated by $R^{2}$.

In models with SAT as a dependent variable (not shown), energy intake did not have an independent contribution to SAT accumulation beyond that explained by percent body fat. This finding is not surprising, as SAT correlated very closely with percent body fat (Pearson correlation $r=0.88$, $P<.0001)$.

5.1. Discussion. Our principal finding was that self-reported energy intake was associated with higher IAT in this diverse and well-defined, naturalistic, community-based cohort of women undergoing the menopausal transition. This relationship of energy intake and IAT was independent of selfreported physical activity and menopausal status and was stronger in Caucasian than in African American women.

Preferential IAT loss is known to occur in weight loss experiments. However, further studies are needed to explore the allometric relationships between IAT and body size in weight gain [8]. IAT is a labile adipose tissue depot. IAT adipocytes have higher lipolysis rates and secretory protein expression than subcutaneous adipocytes [22]. However, during positive energy balance IAT is hypothesized to be a secondary fat storage pool that accumulates only after subcutaneous stores are full [23]. Our cross-sectional data suggest preferential IAT accumulation at higher self-reported 
TABLE 2: Multivariable models of association between self-reported energy intake and intra-abdominal adipose tissue.

\begin{tabular}{|c|c|c|c|c|c|c|}
\hline \multirow{2}{*}{ Parameters } & \multicolumn{2}{|c|}{ Model 1* } & \multicolumn{2}{|c|}{ Model 2** } & \multicolumn{2}{|c|}{ Model $3^{* * *}$} \\
\hline & Estimate $^{\mathrm{a}}$ & $P$-value & Estimate $^{\mathrm{a}}$ & $P$-value & Estimate $^{\mathrm{a}}$ & $P$-value \\
\hline \multicolumn{7}{|l|}{ Lifestyle factors } \\
\hline Energy intake, for every $500 \mathrm{kcal} /$ day & 0.058 & 0.025 & 0.058 & 0.025 & 0.119 & 0.001 \\
\hline Physical activity (KPAS score) & - & - & -0.038 & 0.016 & -0.035 & 0.024 \\
\hline \multicolumn{7}{|l|}{ Confounders } \\
\hline African American versus Caucasian women & -0.183 & $<0.001$ & -0.204 & $<0.001$ & 0.182 & 0.170 \\
\hline Postmenopausal versus pre-/perimenopausal women & 0.106 & 0.054 & 0.115 & 0.035 & 0.124 & 0.023 \\
\hline Energy intake* ethnicity interaction & - & - & - & - & -0.120 & 0.018 \\
\hline \multicolumn{7}{|l|}{ Correction factors } \\
\hline Percent body fat, for every $5 \%$ & 0.192 & $<0.001$ & 0.183 & $<0.001$ & 0.186 & $<0.001$ \\
\hline Percent body fat ${ }^{2}$ & -0.022 & 0.001 & -0.024 & 0.001 & -0.024 & 0.001 \\
\hline Age & 0.010 & 0.262 & 0.010 & 0.307 & 0.011 & 0.241 \\
\hline $\mathrm{Age}^{2}$ & 0.004 & 0.041 & 0.005 & 0.023 & 0.004 & 0.038 \\
\hline Current smoking & 0.151 & 0.017 & 0.116 & 0.075 & 0.129 & 0.045 \\
\hline \multicolumn{7}{|l|}{ Income } \\
\hline Lower than $\$ 50,000$ & -0.053 & 0.457 & -0.035 & 0.632 & -0.049 & 0.496 \\
\hline$\$ 50,000$ to $\$ 75,000$ & -0.052 & 0.405 & -0.034 & 0.579 & -0.041 & 0.504 \\
\hline$R^{2}$ & \multicolumn{2}{|c|}{$56 \%$} & \multicolumn{2}{|c|}{$57 \%$} & \multicolumn{2}{|c|}{$58 \%$} \\
\hline
\end{tabular}

${ }^{a}$ logarithmically transformed intra-abdominal adipose tissue area in $\mathrm{cm}^{2}(\log \mathrm{IAT})$.

*Model 1 was adjusted for risk groups (ethnicity, menopausal status), income, age and percent body fat.

**Model 2 was adjusted the same as Model 1 plus low physical activity (Kaiser Physical Activity Survey score) and smoking status.

***Model 3 was adjusted the same as Model 2 plus energy intake* ethnicity interaction.

TABle 3: Multivariable models of association between self-reported energy intake with ratio of intra-abdominal adipose tissue to subcutaneous abdominal adipose tissue (IAT : SAT ratio).

\begin{tabular}{|c|c|c|c|c|c|c|}
\hline \multirow{2}{*}{ Parameters } & \multicolumn{2}{|c|}{ Model 1* } & \multicolumn{2}{|c|}{ Model $2 * *$} & \multicolumn{2}{|c|}{ Model $3^{* * *}$} \\
\hline & Estimate & $P$-value & Estimate & $P$-value & Estimate & $P$-value \\
\hline \multicolumn{7}{|l|}{ Lifestyle factors } \\
\hline Energy intake, for every $500 \mathrm{kcal} /$ day & 0.017 & 0.013 & 0.017 & 0.012 & 0.039 & $<0.001$ \\
\hline Physical activity (per 1 point KPAS score) & - & - & -0.009 & 0.036 & -0.008 & 0.058 \\
\hline \multicolumn{7}{|l|}{ Confounders } \\
\hline African American versus Caucasian women & -0.058 & $<0.001$ & -0.063 & $<0.001$ & 0.079 & 0.067 \\
\hline Postmenopausal versus pre-/perimenopausal women & 0.033 & 0.019 & 0.035 & 0.013 & 0.038 & 0.006 \\
\hline Energy intake* ethnicity interaction & - & - & - & - & -0.044 & 0.001 \\
\hline \multicolumn{7}{|l|}{ Correction factors } \\
\hline Percent body fat, for every $5 \%$ & -0.011 & 0.012 & -0.013 & 0.003 & -0.013 & 0.005 \\
\hline Percent body fat ${ }^{2}$ & -0.005 & 0.003 & -0.006 & 0.001 & -0.006 & 0.001 \\
\hline Age & 0.005 & 0.151 & 0.004 & 0.079 & 0.005 & 0.045 \\
\hline $\mathrm{Age}^{2}$ & 0.001 & 0.058 & 0.001 & 0.063 & 0.001 & 0.109 \\
\hline Current smoking & 0.038 & 0.020 & 0.029 & 0.086 & 0.034 & 0.040 \\
\hline \multicolumn{7}{|l|}{ Income } \\
\hline Lower than & -0.020 & 0.264 & -0.017 & 0.349 & -0.023 & 0.213 \\
\hline$\$ 50,000$ to $\$ 75,000$ & -0.004 & 0.786 & -0.001 & 0.964 & -0.003 & 0.838 \\
\hline$R^{2}$ & \multicolumn{2}{|c|}{$23 \%$} & \multicolumn{2}{|c|}{$24 \%$} & \multicolumn{2}{|c|}{$28 \%$} \\
\hline
\end{tabular}

*Model 1 was adjusted for risk groups (ethnicity, menopausal status), income, age and percent body fat.

**Model 2 was adjusted the same as Model 1 plus physical activity (Kaiser Physical Activity Survey score-every point indicates higher physical activity) and smoking status.

***Model 3 was adjusted the same as Model 2 plus energy intake* ethnicity interaction. 
caloric intake in mid-life women. This finding should be confirmed in longitudinal explorations of the allometric relationship between IAT and body fat.

To our knowledge, this is the first study in a naturalistic community-based cohort to analyze the joint associations of self-reported energy intake and physical activity with preferential IAT accumulation. Our current findings extend the previous work conducted by our group demonstrating that that regular moderate physical activity (meeting physical activity guidelines for healthy adults) was associated with lower IAT area in midlife women, independent of total adiposity [6]. Although exercise has been regarded as a specific therapy to reduce IAT accumulation [24], our findings suggest that lower energy intake also has significant independent protective effects on preferential IAT deposition beyond those of physical activity, and these effects are independent of total adiposity [25]. Higher self-reported energy intake is related to IAT to SAT ratio higher at all body sizes in mid-life women. Thus, excess energy appears to be preferentially partitioned into intra-abdominal rather than subcutaneous abdominal area at all body sizes.

Abdominal adiposity may be a growing problem for African Americans. Although, Caucasian women have more IAT adjusted for percent body fat than African American women [20, 26-28], over the past 10 years, the largest increase in abdominal obesity occurred in the African American population [29]. The association between self-reported energy intake and IAT appears stronger in Caucasian than in African American women. During energy intake restriction, Caucasian women tend to lose more IAT than African American women, however, the differences disappear after adjustment for baseline IAT or the amount of total fat lost $[30,31]$. The quantitative differences in energy intake do not explain why African American women partition proportionally less fat into the IAT compartment. These ethnic differences in the association between self-reported energy intake and IAT can be a result of differential reporting bias among Caucasian and African American women [14]. Since the problem of abdominal obesity may be growing more extreme for African American women, it is urgent to determine factors associated with this increasing risk.

The findings in our study are congruent with a recently published small longitudinal study suggesting preferential IAT increase related to menopause in Caucasian women [32]. However, longitudinal study of African American women suggested that the greatest IAT accumulation occurs during young adulthood; no significant 5 -year IAT change was observed in women between ages 50 to 69 [33].

The strength of our study is that the women were studied in their naturalistic, community-based environment, they were demographically similar, and their menopausal status was well defined. Unlike the majority of previous studies exploring correlates of IAT distribution [26, 27, 34-37], we adjusted our multivariable models for income.

A limitation of our study is the lack of longitudinal followup of IAT, which would clarify the effects of menopause on IAT accumulation and factors associated with IAT gain during the menopausal transition. Measurement error, a result of self-reporting energy intake without biomarker validation for the Food Frequency Questionnaire, may have affected the association between energy intake and IAT. We made our best effort to adjust the energy intake, derived from the Food Frequency Questionnaire, using factors previously shown to correct for the measurement error [14]: relative body fat mass, ethnicity, age, physical activity, smoking, and annual income. Since measurements error biases toward the null hypothesis, and since these data show strong and significant associations for energy intake, measurement error is unlikely to be a serious problem in this report.

In summary, higher self-reported energy intake in midlife women was associated with preferential compartmentalization of fat into the IAT depot, particularly for Caucasian women. A longitudinal follow-up study is needed to explore the allometric relationship between IAT and body fat, as well as the effects of diet quality (such as macronutrient composition), socioeconomic and lifestyle risk factors, menopause, insulin resistance, and other atherosclerosis risk markers on increases in IAT, particularly in African American women.

\section{Conflict of Interests}

The authors declare that there is no conflict of interests.

\section{Acknowledgments}

The Study of Women's Health Across the Nation (SWAN) has grant support from the National Institutes of Health (NIH), DHHS, through the National Institute on Aging (NIA), the National Institute of Nursing Research (NINR) and the NIH Office of Research on Women's Health (ORWH) (Grants NR004061; AG012505, AG012535, AG012531, AG012539, AG012546, AG012553, AG012554, AG012495). The SWAN Fat Patterning Study is supported by the National Heart, Lung and Blood Institute (Grant HL067128) and the Charles J. and Margaret Roberts Trust. The content of this paper is solely the responsibility of the authors and does not necessarily represent the official views of the NIA, NINR, ORWH or the NIH. The authors declare no conflict of interest. The Clinical Centers are University of Michigan, Ann Arbor-Siobán Harlow, PI 2011-present, MaryFran Sowers, PI 1994-2011; Massachusetts General Hospital, Boston, MA—Joel Finkelstein, PI 1999-present; Robert Neer, PI 1994-1999; Rush University, Rush University Medical Center, Chicago, IL-Howard Kravitz, PI 2009-present; Lynda Powell, PI 1994-2009; University of California, Davis/Kaiser-Ellen Gold, PI; University of California, Los Angeles-Gail Greendale, PI; Albert Einstein College of Medicine, Bronx, NY-Carol Derby, PI 2011-present, Rachel Wildman, PI 2010-2011; Nanette Santoro, PI 2004-2010; University of Medicine and Dentistry-New Jersey Medical School, Newark-Gerson Weiss, PI 1994-2004; and the University of Pittsburgh, Pittsburgh, PA-Karen Matthews, PI. The NIH Program Office: National Institute on Aging, Bethesda, MD—Winifred Rossi 2012; Sherry Sherman 19942012; Marcia Ory 1994-2001; National Institute of Nursing Research, Bethesda, MD_-Program Officers. The Central Laboratory at the University of Michigan in Ann Arbor is 
led by Daniel McConnell (Central Ligand Assay Satellite Services). The Coordinating Center: University of Pittsburgh, Pittsburgh, PA-Kim Sutton-Tyrrell, Co-PI 2001-present; Maria Mori Brooks Co-PI 2012; New England Research Institutes, Watertown, MA-Sonja McKinlay, PI 1995-2001. The Steering Committee Chair is Susan Johnson, and the Former Chairs were Jenny Kelsey and Chris Gallagher. The authors thank the study staff at each site and all the women who participated in SWAN, and acknowledge Jeremy Z. Fields for his careful editorial review of the manuscript and improving its clarity.

\section{References}

[1] T. Coutinho, K. Goel, D. Corrêa De S et al., "Central obesity and survival in subjects with coronary artery disease: a systematic review of the literature and collaborative analysis with individual subject data," Journal of the American College of Cardiology, vol. 57, no. 19, pp. 1877-1886, 2011.

[2] S. Fujioka, Y. Matsuzawa, K. Tokunaga, and S. Tarui, "Contribution of intra-abdominal fat accumulation to the impairment of glucose and lipid metabolism in human obesity," Metabolism, vol. 36, no. 1, pp. 54-59, 1987.

[3] M. A. M. Jacobs-Van Der Bruggen, G. Bos, W. J. Bemelmans, R. T. Hoogenveen, S. M. Vijgen, and C. A. Baan, "Lifestyle interventions are cost-effective in people with different levels of diabetes risk: results from a modeling study," Diabetes Care, vol. 30, no. 1, pp. 128-134, 2007.

[4] E. A. Molenaar, J. M. Massaro, P. F. Jacques et al., "Association of lifestyle factors with abdominal subcutaneous and visceral adiposity the framingham heart study," Diabetes Care, vol. 32, no. 3, pp. 505-510, 2009.

[5] I. Janssen, L. H. Powell, R. Kazlauskaite, and S. A. Dugan, "Testosterone and visceral fat in midlife women: the study of women's health across the nation (SWAN) fat patterning study," Obesity, vol. 18, no. 3, pp. 604-610, 2010.

[6] S. A. Dugan, S. A. Everson-Rose, K. Karavolos, E. F. Avery, D. E. Wesley, and L. H. Powell, "Physical activity and reduced intraabdominal fat in midlife african-American and white women," Obesity, vol. 18, no. 6, pp. 1260-1265, 2010.

[7] Y. D. Tchoukalova, S. B. Votruba, T. Tchkonia, N. Giorgadze, J. L. Kirkland, and M. D. Jensen, "Regional differences in cellular mechanisms of adipose tissue gain with overfeeding," Proceedings of the National Academy of Sciences of the United States of America, vol. 107, no. 42, pp. 18226-18231, 2010.

[8] C. E. Hallgreen and K. D. Hall, "Allometric relationship between changes of visceral fat and total fat mass," International Journal of Obesity, vol. 32, no. 5, pp. 845-852, 2008.

[9] T. B. Chaston and J. B. Dixon, "Factors associated with percent change in visceral versus subcutaneous abdominal fat during weight loss: findings from a systematic review," International Journal of Obesity, vol. 32, no. 4, pp. 619-628, 2008.

[10] M. R. Sowers, S. L. Crawford, B. Sternfeld et al., "SWAN: a multi-center, multi-ethnic, community-based cohort study of women and the menopausal transition," in Menopause: Biology and Pathobiology, R. Lobo, J. Kelsey, and R. Marcus, Eds., pp. 175-188, Academic Press, San Diego, Calif, USA, 2000.

[11] R. J. Santen, D. C. Allred, S. P. Ardoin et al., "Postmenopausal hormone therapy: an endocrine society scientific statement," The Journal of Clinical Endocrinology \& Metabolism, vol. 95, no. 7, supplement 1, pp. s1-s66, 2010.
[12] G. Block, A. M. Hartman, and C. M. Dresser, "A data-based approach to diet questionnaire design and testing," American Journal of Epidemiology, vol. 124, no. 3, pp. 453-469, 1986.

[13] K. M. Tomey, M. R. Sowers, C. Crandall, J. Johnston, M. Jannausch, and M. Yosef, "Dietary intake related to prevalent functional limitations in midlife women," American Journal of Epidemiology, vol. 167, no. 8, pp. 935-943, 2008.

[14] M. L. Neuhouser, L. Tinker, P. A. Shaw et al., "Use of recovery biomarkers to calibrate nutrient consumption selfreports in the Women's Health Initiative," American Journal of Epidemiology, vol. 167, no. 10, pp. 1247-1259, 2008.

[15] V. Kipnis, A. F. Subar, D. Midthune et al., "Structure of dietary measurement error: results of the OPEN biomarker study," American Journal of Epidemiology, vol. 158, no. 1, pp. 14-21, 2003.

[16] B. E. Ainsworth, B. Sternfeld, M. T. Richardson, and K. Jackson, "Evaluation of the kaiser physical activity survey in women," Medicine and Science in Sports and Exercise, vol. 32, no. 7, pp. 1327-1338, 2000.

[17] B. Lee, E. O. Im, and W. Chee, "Psychometric properties of the KPAS in diverse ethnic groups of midlife women," Western Journal of Nursing Research, vol. 31, no. 8, pp. 1014-1034, 2009.

[18] G. Fitzmaurice, N. Laird, and J. Ware, Applied Longitudinal Analysis, vol. 407, Wiley-Interscience, 2004.

[19] E. J. Pedhazur, "Curvilinear regression analysis," in Multiple Regression in Behavioral Research, pp. 513-559, Harcourt Brace College Publishers, Orlando, Fla, USA, 1997.

[20] P. T. Katzmarzyk, G. A. Bray, F. L. Greenway et al., "Racial differences in abdominal depot-specific adiposity in white and African American adults," American Journal of Clinical Nutrition, vol. 91, no. 1, pp. 7-15, 2010.

[21] E. Vittinghoff, Regression Methods in Biostatistics: Linear, Logistic, Survival, and Repeated Measures Models, Springer, 2005.

[22] P. Mauriege, A. Marette, C. Atgie et al., "Regional variation in adipose tissue metabolism of severely obese premenopausal women," Journal of Lipid Research, vol. 36, no. 4, pp. 672-684, 1995.

[23] A. D. Sniderman, R. Bhopal, D. Prabhakaran, N. Sarrafzadegan, and A. Tchernof, "Why might South Asians be so susceptible to central obesity and its atherogenic consequences? The adipose tissue overflow hypothesis," International Journal of Epidemiology, vol. 36, no. 1, pp. 220-225, 2007.

[24] S. R. Smith and J. J. Zachwieja, "Visceral adipose tissue: a critical review of intervention strategies," International Journal of Obesity, vol. 23, no. 4, pp. 329-335, 1999.

[25] J. P. Desprs, "Excess visceral adipose tissue/ectopic fat: the missing link in the obesity paradox?" Journal of the American College of Cardiology, vol. 57, no. 19, pp. 1887-1889, 2011.

[26] J. O. Hill, S. Sidney, C. E. Lewis, K. Tolan, A. L. Scherzinger, and E. R. Stamm, "Racial differences in amounts of visceral adipose tissue in young adults: the CARDIA (coronary artery risk development in young adults) study," American Journal of Clinical Nutrition, vol. 69, no. 3, pp. 381-387, 1999.

[27] E. W. Demerath, S. S. Sun, N. Rogers et al., "Anatomical patterning of visceral adipose tissue: race, sex, and age variation," Obesity, vol. 15, no. 12, pp. 2984-2993, 2007.

[28] J. A. Kanaley, I. Giannopoulou, G. Tillapaugh-Fay, J. S. Nappi, and L. L. Ploutz-Snyder, "Racial differences in subcutaneous and visceral fat distribution in postmenopausal black and white women," Metabolism, vol. 52, no. 2, pp. 186-191, 2003. 
[29] M. A. Beydoun and Y. Wang, "Gender-ethnic disparity in BMI and waist circumference distribution shifts in US adults," Obesity, vol. 17, no. 1, pp. 169-176, 2009.

[30] R. L. Weinsier, G. R. Hunter, B. A. Gower, Y. Schutz, B. E. Darnell, and P. A. Zuckerman, "Body fat distribution in white and black women: different patterns of intraabdominal and subcutaneous abdominal adipose tissue utilization with weight loss," American Journal of Clinical Nutrition, vol. 74, no. 5, pp. 631-636, 2001.

[31] B. J. Nicklas, K. E. Dennis, D. M. Berman, J. Sorkin, A. S. Ryan, and A. P. Goldberg, "Lifestyle intervention of hypocaloric dieting and walking reduces abdominal obesity and improves coronary heart disease risk factors in obese, postmenopausal, African-American and Caucasian women," Journals of Gerontology, vol. 58, no. 2, pp. M181-M189, 2003.

[32] R. M. Franklin, L. Ploutz-Snyder, and J. A. Kanaley, "Longitudinal changes in abdominal fat distribution with menopause," Metabolism, vol. 58, no. 3, pp. 311-315, 2009.

[33] K. G. Hairston, A. Scherzinger, C. Foy et al., "Five-year change in visceral adipose tissue quantity in a minority cohort: the insulin resistance atherosclerosis study (IRAS) family study," Diabetes Care, vol. 32, no. 8, pp. 1553-1555, 2009.

[34] J. P. Després, C. Couillard, J. Gagnon et al., "Race, visceral adipose tissue, plasma lipids, and lipoprotein lipase activity in men and women: the health, risk factors, exercise training, and genetics (HERITAGE) family study," Arteriosclerosis, Thrombosis, and Vascular Biology, vol. 20, no. 8, pp. 1932-1938, 2000.

[35] G. A. Bray, K. A. Jablonski, W. Y. Fujimoto et al., "Relation of central adiposity and body mass index to the development of diabetes in the Diabetes Prevention Program," American Journal of Clinical Nutrition, vol. 87, no. 5, pp. 1212-1218, 2008.

[36] D. J. Hoffman, Z. Wang, D. Gallagher, and S. B. Heymsfield, "Comparison of visceral adipose tissue mass in adult AfricanAmericans and whites," Obesity Research, vol. 13, no. 1, pp. 66-74, 2005.

[37] J. F. Carroll, A. L. Chiapa, M. Rodriquez et al., "Visceral fat, waist circumference, and BMI: impact of race/ethnicity," Obesity, vol. 16, no. 3, pp. 600-607, 2008. 


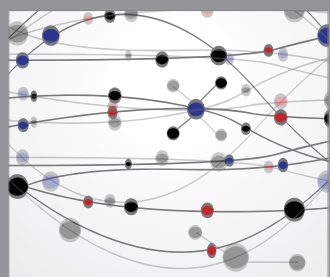

The Scientific World Journal
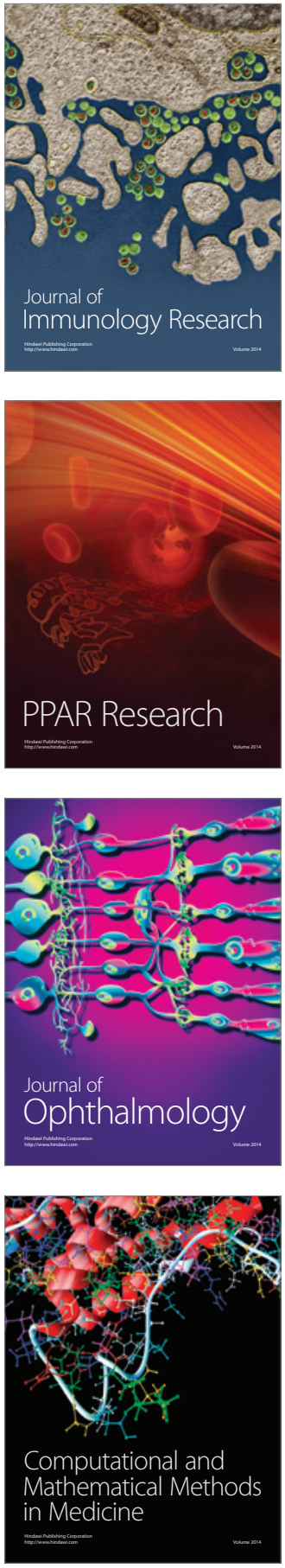

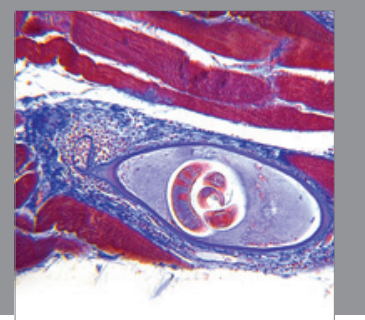

Gastroenterology

Research and Practice
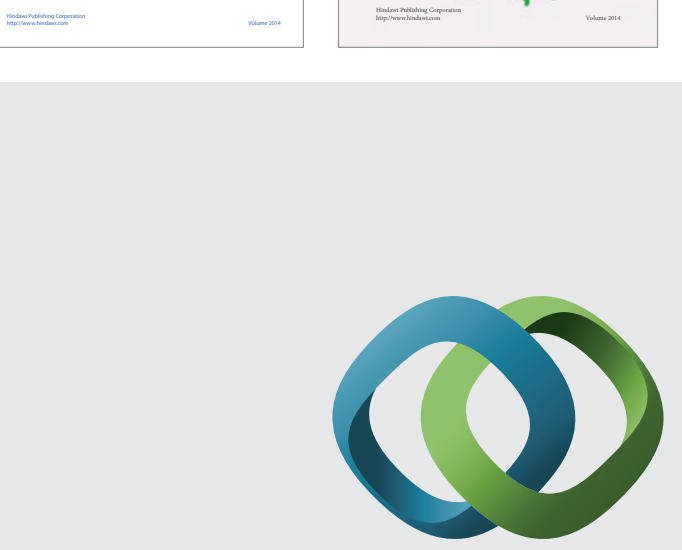

\section{Hindawi}

Submit your manuscripts at

http://www.hindawi.com
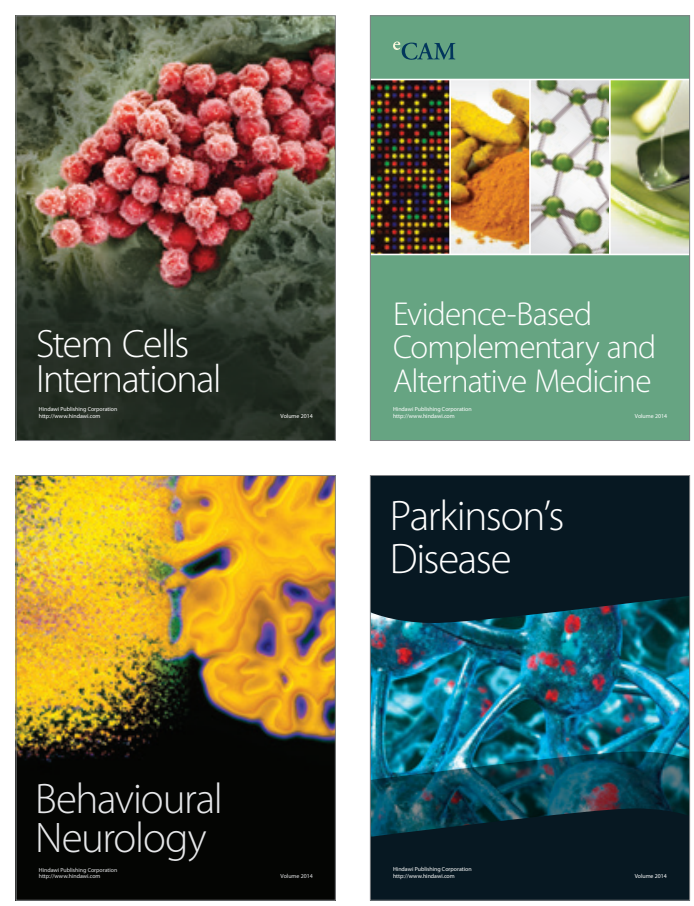

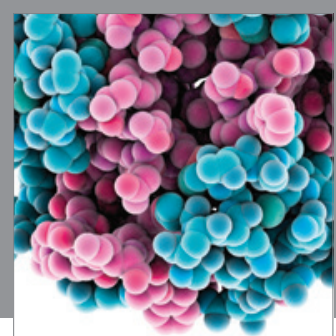

Journal of
Diabetes Research

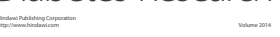

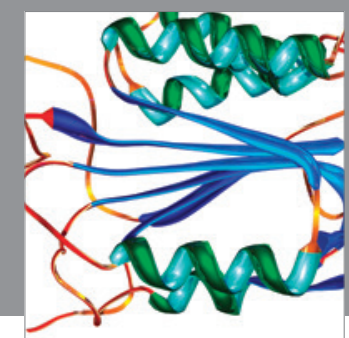

Disease Markers
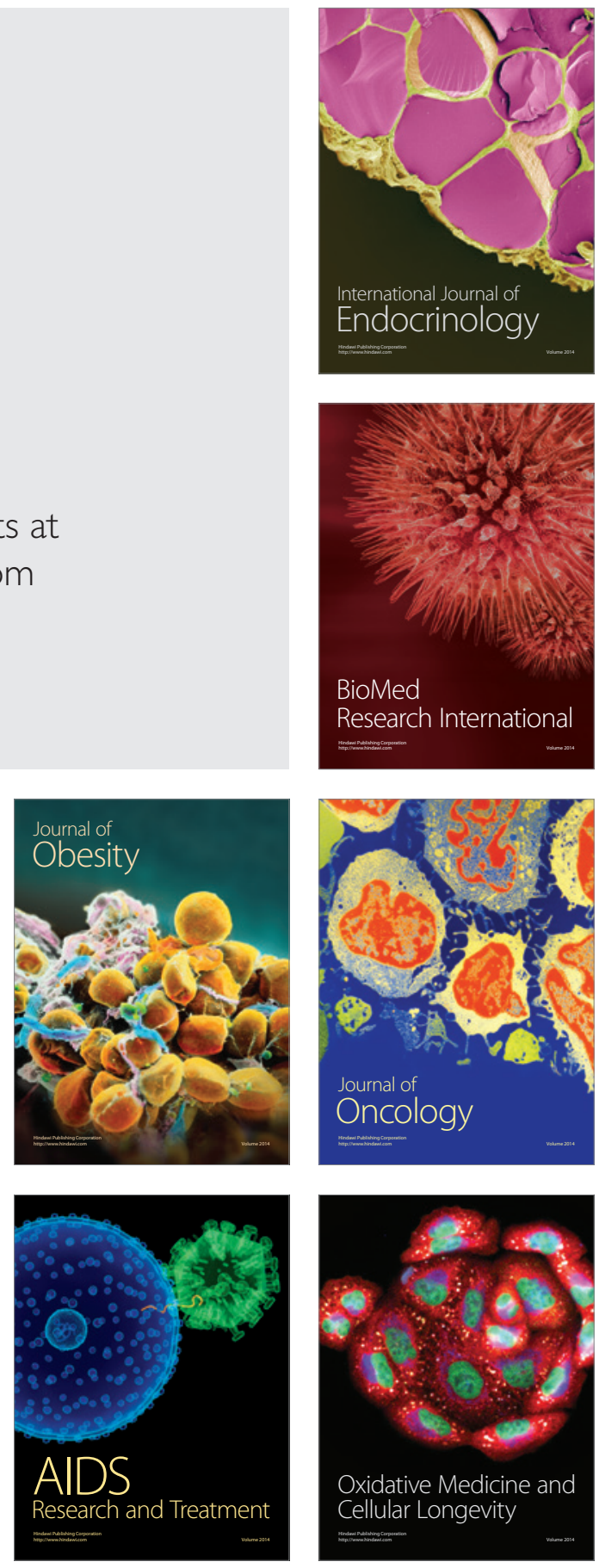